\title{
Palmas: lugar central ou enclave no centro-norte do Brasil?
}

\section{Palmas: central place or enclave in the northern centre of Brazil?}

Thiago José Arruda de Oliveira - Doutorando do Programa de Pós-Graduação em Desenvolvimento Regional e Agronegócios - UNIOESTE/Toledo e pesquisador bolsista pela CAPES. E-mail: thiago.arruda85@gmail.com

Moacir Piffer - Doutor em Desenvolvimento Regional pela Universidade de Santa Cruz do Sul (UNISC). Mestre em Desenvolvimento Econômico pela Universidade Federal do Paraná (UFPR). Bacharel em Ciências Econômicas pela Universidade Estadual de Maringá (UEM). Professor do Programa de Pós-graduação em Desenvolvimento Regional e Agronegócio da Universidade Estadual do Oeste do Paraná (UNIOESTE)/ Campus de Toledo. E-mail: mopiffer@yahoo.com.br

\section{Resumo}

Este artigo analisa a relação da cidade de Palmas/TO com a rede urbana do estado do Tocantins e também com as microrregiões limítrofes localizadas no Maranhão e Pará. Para esta análise, levanta-se a seguinte hipótese: a capital tocantinense é um lugar central, explicado pelo postulado de Walter Christaller ou é desprovido de qualquer relação espacial na sua região - enclave. Emprega-se o Índice de Herfindahl-Hirschman para compreender a estruturação desta rede, observando o nível de concentração de serviços nesta região. Os resultados mostram que Palmas exerce o poder de comando para poucos municípios - Paraíso, Porto Nacional e Miracema. A tendência é aumentar a sua área de influência para as demais localidades situadas ao redor de Gurupi, no sudoeste do estado. Portanto a capital do Tocantins não é um enclave. Porém não se encaixa no conceito de lugar central ao nível de Centro-Norte.

\section{Palavras-chave}

Lugar central, análise regional, serviços urbanos, espaço econômico.

\begin{abstract}
This paper analyzes the relation of the city of Palmas/TO with its urban network of the Tocantins state and as well with its marginal microregions located in Maranhão and Pará. It is assumed that the capital of Tocantins state or is a central place, explained by the theorem of Walter Christaller, or absent of any spatial relation with its region - an enclave. The HerfindahlHirschmann index is utilized in order to understand the structure of this network, observing the level of service concentration in this region. Results show that Palmas is exercising commandership only for a few municipalities such as Paraíso, Porto Nacional and Miracema. Apparently, there is a tendency of increasing its area of influence to other locations near to the Gurupi area, in the southwest of the state. Thus, the capital of Tocantins is not an enclave, but does not perform as a central place referring to the northern centre.
\end{abstract}

\section{Keywords}

Central place, regional analysis, urban services, economic space. 


\section{INTRODUÇÃO}

A capital do estado do Tocantins, Palmas, foi planejada em 1989 com o objetivo de ser a sede política da mais nova Unidade Federativa do Brasil. Este núcleo urbano surgiu como um local de referência não apenas para a população do Tocantins, mas também para aqueles que residem em outros estados. Após uma década de existência, tornou-se a maior do estado em quantidade de habitantes (BRITO, 2009; LIRA, 2011; RODRIGUES, 2010).

Devido ao crescimento populacional alcançado em seus primeiros dez anos, Palmas transfigurou-se em objeto de estudos voltados para a compreensão de sua relação com as demais localidades ${ }^{1}$. Ou seja, estas pesquisas demonstram que a capital tocantinense tornou-se um importante agente capaz de comandar os demais núcleos urbanos do seu entorno, principalmente no que tange à oferta de bens e serviços para as demais cidades. Todavia, apesar desta qualidade, a capital tocantinense possui fraco poder de comando no que concerne à estruturação espacial (BECKER, 2005; BRASIL, 2008).

Para contornar esta deficiência, Palmas e demais núcleos precisam rehierarquizar o território Centro-Norte. Esta afirma ${ }^{2}$ ção é baseada na teoria de lugar central, apresentado por Christaller, que trata da distribuição espacial dos centros urbanos na economia regional (BRASIL, 2008; RICHARDSON, 1981).

Diante dessas constatações, este artigo analisa a função de Palmas, se corresponde à teoria de lugar central ou é um enclave urbano. Esta pesquisa se justifica por tratar de uma oportunidade que o estado do Tocantins possui em internalizar os ganhos produtivos gerados, podendo diminuir a depend ${ }^{3} \hat{e}$ ncia por capital e serviços oferecidos pelas grandes capitais do Centro-Sul.

Para realizar tal investigação, buscam-se evidências empíricas em trabalhos científicos correlatos, além de utilizar o Indicador Hirschman-Herfindahl (IHH). O objetivo desta metodologia é compreender a situação da estrutura urbana do estado do Tocantins e de municípios próximos, como Marabá, Parauapebas, Redenção e Conceição do Araguaia, no Pará, e Imperatriz, Porto Franco e Balsas, no Maranhão.

\section{A ÁREA DE MERCADO E SUA REGIÃO DE INFLUÊNCIA}

Walter Christaller (1893-1969) elaborou a Teoria do Lugar Central (TLC) concebendo que um núcleo urbano, denominado lugar central, hierarquize toda

Duas dissertações em anos recentes tratam desta temática: Brito (2009) e Oliveira (2012).

2 O Território Esstratégico do Centro-Norte, que engloba as microrregiões de seis estados: Mato Grosso, Pará, Maranhão, Piauí, Bahia e Tocantins.

3 Enclave é um centro urbano isolado, ao contrário da concepção de lugar central.

4 Obra original desta teoria: Christäller, W. Central places in southern Germany. Englewood Cliffs/NJ: Prentice-Hall, 1966. 
a rede de cidades, estabelecendo relação de dependência com os demais por meio da oferta de bens e serviços coletivos.

Existem razões para que uma cidade torne-se um lugar central. Entre elas estão a alta densidade populacional, o nível de renda entre seus moradores, o grau de concorrência entre os estabelecimentos e a estrutura sociocultural. Estes s $\mathrm{s}^{5}$ ão fatores que aumentam a oferta e demanda de bens e serviços urbanos em determinada localidade. O número de funções que este centro executa é outro fator determinante para que se torne um lugar central. Entretanto, os custos de transporte podem limitar o acesso e a disponibilidade destes fatores (RICHARDSON, 1981).

A hierarquia dos lugares centrais, portanto, baseia-se nas funções que estes centros exercem na região, no tamanho de sua população e nas distâncias entre as cidades. Em relação a sua distribuição espacial, é influenciada pela estrutura da rede de transporte e as facilidades de deslocamento nestas vias de tráfego.

Porém as relações hierárquicas dissimulam as dependências existentes entre as localidades que ofertam serviço superior, que estão relacionados à especialização (especialidades médicas e cursos de ensino superior/pósgraduação, por exemplo) com aquelas de caráter inferior, que se encontra tanto em lugares centrais como em pequenos locais - clínicas gerais e escolas primárias (RICHARDSON, 1981).

Portanto, todas as cidades menores estão influenciadas pelas decisões dos centros maiores, que agrupam a maioria das unidades produtivas relacionadas aos serviços especializados. Nota-se esta afirmação nos países em desenvolvimento, onde toda a produção está concentrada em um ou dois centros urbanos que direcionam o seu comércio para a exportação de produtos primários, de baixo valor agregado, que são facilmente extraídos ou cultivados em seu solo. Como a fertilidade da terra e a disponibilidade de recursos não se encontram uniformemente na região, criam-se lugares de concentração, tal como ocorreu em Manaus durante o Ciclo da Borracha no início do século XX, que recebia todo o látex extraído nas diversas seringueiras da Amazônia Ocidental e exportava para os demais países (HILHORST, 1981).

Para que a produção não se aglomere em um único ponto, é necessário que ocorram efeitos de encadeamentos a partir dos núcleos. Desta forma, evita-se o surgimento de enclaves, que s $\mathrm{s}^{6}$ ão centros urbanos que estão distantes do contexto

Muitos serviços centrais são de natureza cultural. Por exemplo, a Oktorberfest em Blumenau/ SC, festa típica da cultura alemã, e o Círio de Nazaré em Belém/PA, de caráter religioso.

6 O efeito de encadeamentos para trás e para frente são responsáveis pelas interações de retornos crescentes de escala. Estes inter-relacionamentos podem ser importantes se os insumos forem empregados na fabricação de produtos de alta especialização. Entretanto, têm-se o dilema do 
produtivo da região, desprovidas de coerência interna nas suas interconexões, podendo ter maiores vinculações com o resto do mundo do que com o mercado interno local ou regional. Estes monopolizam a produção tecnológica, sendo que a maior parte de suas relações ocorre fora da área que circunda (AMARAL FILHO, 2001; SANTOS, 2003).

Para que os países não criem enclaves, as cidades devem adaptar-se rapidamente aos novos paradigmas produtivos e organizacionais. Portanto, os atores locais devem empenhar-se em gerar inovações a serem aplicadas no processo produtivo. O propósito desta iniciativa é diversificar e aumentar a produção, possibilitando a maior inserção dos núcleos no sistema urbano regional. Neste sentido, o surgimento de circuitos superiores está enraizado na aprendizagem e na capacidade deste novo conhecimento na criação de novos processos produtivos (DINIZ; GONÇALVES, 2005).

Becker (2005) complementa essa afirmação frisando que o estado necessita articular-se com a sociedade civil local, contando com a sua participação e cooperação, pois estes são os possuidores dos meios de produção e distribuição, interagindo o mercado local com o nacional.

Portanto, é importante identificar adensamentos populacionais e atribuir-lhes sinergia a partes do território, contribuindo para o fortalecimento do sistema urbano regional. A vantagem em promover esta reestruturação é aumentar a frequência de transações econômicas internas, minimizando os custos de transporte e aprisionando os rendimentos gerados. Contudo, esta concepção é difícil de ser adotada nos países subdesenvolvidos por causa do predomínio de atividades de pequena escala, limitando o número de compradores e vendedores (SANTOS, 2003).

Perante tais informações, consta-se que a Teoria do Lugar Central difunde as relações econômicas que as cidades estabelecem por meio dos serviços urbanos. Porém, nem todas as localidades possuem a capacidade de tornar-se um centro regional por causa de suas limitações - fraca densidade demográfica, difícil acesso e/ou baixa aptidão para produção. Por isso, emergem os enclaves, que impossibilitam o aparecimento de interações espaciais com outras cidades do sistema regional.

\section{PALMAS E SEU ENTORNO}

$\mathrm{Na}$ tentativa de contornar o problema dos enclaves no Brasil, propõe-se a construção de territórios integrados e policêntricos, articulando e orientando

lugar central: a capacidade produtiva do bem final concentra-se em lugares com mercados relativamente grandes (STORPER; VENABLES, 2005). 
os agentes no processo do desenvolvimento regional. Palmas/TO é um destes encarregados no processo de estruturar e comandar a macrorregião CentroNorte $^{7}$, tendo companhia em nível sub-regional das localidades de Marabá/PA, Imperatriz/MA, Araguaína/TO e Barreiras/BA (BRASIL, 2008).

Becker (2005) afirma que a capital do Tocantins possui a capacidade de formar um subsistema espacial devido ao surgimento de adensamentos urbanos em seu entorno ${ }^{8}$. Outro fator que contribui para que ocorra esta articulação regional é a dispersão de centros sub-regionais, como Marabá, Imperatriz e Araguaína, e outros de caráter local - Balsas/MA e Redenção/PA. Estas localidades estão mais próximas da capital do Tocantins do que das suas capitais estaduais, como mostra a Figura 1.

Figura 1 - Distância rodoviária dos centros sub-regionais/locais para Palmas/ TO, Belém/PA e São Luís/MA - 2012.

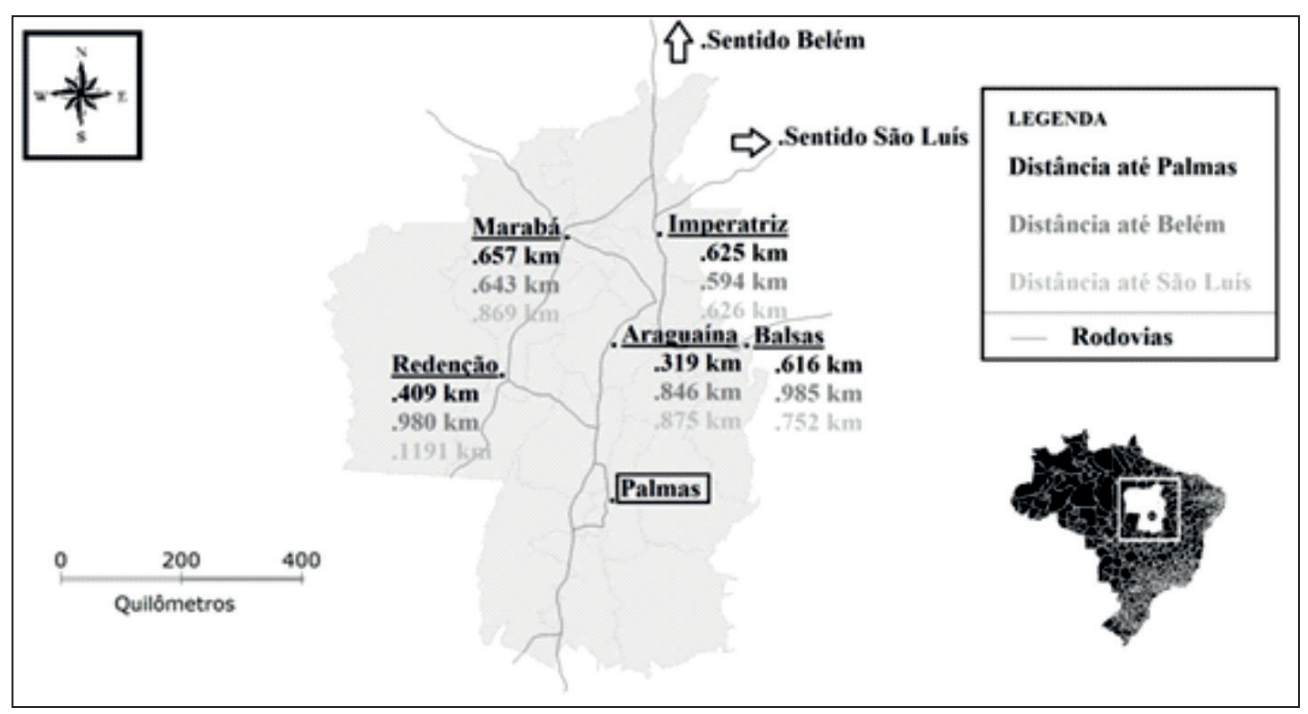

Fonte: Google Maps e IBGE. Elaboração própria.

Os dois centros sub-regionais: Imperatriz e Marabá situam-se entre a capital do Tocantins e a sua capital estadual, tendo pouca diferença em termos de distância rodoviária. Por outro lado, Palmas é próximo dos centros locais: Balsas/MA e Redenção/PA, comparando-se com Belém e São Luís, portanto, tem mais possibilidade de exercer a função de polo macrorregional do que as capitais do Maranhão e Pará.

Engloba as microrregiões de seis estados: Mato Grosso, Pará, Maranhão, Piauí, Bahia e todo o estado do Tocantins.

8 Destacam-se Paraíso/TO - 44.416 hab. e Porto Nacional/TO - 49.146 hab. (Censo 2010 - IBGE). No período de 1991/2000, Porto Nacional estabiliza a sua população, e Paraíso cresceu a 2.28\%. Em compensação, Santa Tereza/TO decresceu 3.38\%. 
Além disso, a cidade-sede do poder público tocantinense possui outras vantagens em relação aos dois núcleos sub-regionais. Primeiro, a sua localização centralizada, servindo como ponto de conexão entre o Centro-Sul e a Amazônia. Segundo, por se tratar de uma capital estadual, ofertam-se serviços que são encontrados apenas nas capitais. Terceiro, a maior parte da popula ${ }^{9}$ ção economicamente ativa está empregada no setor de serviços, sustentando a cadeia produtiva regional, podendo dinamizar os demais núcleos. Por fim, ${ }^{10} e ́$ sede de instituições de ensino e pesquisa, órgãos federais, podendo criar aportes científicos e tecnológicos necessários para promover a articulação territorial (BRASIL, 2008). ${ }^{11}$

Entretanto, apesar desta atração populacional, Palmas possui fraco poder de comando no que tange à estruturação econômica espacial. Não apenas a capital, as cidades do interior tocantinense, além daquelas localizadas nos estados limítrofes, são dependentes de sistemas urbanos localizados em outras regiões do país (BECKER, 2005). ${ }^{12}$

\subsection{A ESTRUTURA URBANA DE PALMAS}

O setor terciário em Palmas experimentou uma ampla diversificação ao longo dos vinte anos de existência, diferente do que ocorreu com o vizinho Porto Nacional, localizado a $60 \mathrm{~km}$ da capital. Este fenômeno deve-se à vinda de grandes empresas atacadistas, a construção de um grande shopping center, e unidades clínicas-hospitalares que aumentaram a funcionalidade urbana da capital. Em contrapartida, pela aproximação geográfica, Porto Nacional transforma-se em uma cidade-dormitório (BESSA e CORADO, 2011).

O fluxo de portuenses para a cidade-sede do poder público estadual é formado principalmente por pacientes que procuram as clínicas especializadas e estudantes universitários, expondo uma relação de dependência espacial entre estes dois núcleos, preferencialmente em relação ao setor de comércio e serviços (BRITO, 2009; OLIVEIRA, 2012).

Entretanto, Porto Nacional possui um distrital agroindustrial e uma usina de biodiesel. Paraíso do Tocantins, também próximo da capital, encontra-se sob esta mesma estrutura industrial, e seus moradores também procuram os serviços

9 Principalmente serviços públicos, de ordem burocrática.

10 Nota-se que no Brasil, as capitais concentram a maior parte da população estadual, da arrecadação de ICMS, e de serviços coletivos - exceto em Santa Catarina.

11 Destaca-se a Universidade Federal do Tocantins - UFT, Embrapa Pesca e Aquicultura, e uma superintendência do Departamento Nacional de Produção Mineral - DNPM.

12 Todo o estado do Tocantins, o sul do Maranhão, o nordeste de Mato Grosso, e o sul do Pará está subordinado ao comando de Goiânia/GO. 
coletivos que a capital oferta. Os outros municípios situados ao redor de Palmas não possuem esta característica econômica, portanto o raio de influ ${ }^{13}$ ência direta da capital está restrito a Porto Nacional e Paraíso, devido às complementaridades produtivas que os núcleos exercem entre eles (BRITO, 2009; OLIVEIRA, 2012).

Diante dessa constatação, procura-se levantar evidências que apontem alguma relação espacial que a capital tocantinense exerce nos demais municípios, direcionando esta análise para aqueles que possuem uma base econômica representativa para a região Centro-Norte. A segunda maior cidade do Maranhão, Imperatriz, possui esta característica, e junto com Palmas, possui grandes quantidades de plantas industriais na região - 400 indústrias entre pequenas, médias e maiores. Por causa de seu tamanho - 251 mil habitantes segundo o Censo-IBGE/2010, atraiu moradores de Esperantina/TO, Araguatins/TO, Axixá/TO, Sítio Novo/TO e São Miguel/TO, na microrregião do Bico do Papagaio, por causa dos serviços de saúde e educação que o município maranhense disponibiliza. Além disso, ônibus e caminhões com mercadorias provenientes destas localidades dirigem-se diariamente para o centro de Imperatriz.

Contudo a rede hospitalar de Palmas também atende à população do Maranhão, ou seja, a capital e Imperatriz exercem atração espacial nos municípios do Bico do Papagaio e do sul maranhense. Porém a polarização de Palmas sobre estas áreas é menor por dois motivos: a distância rodoviária entre a capital e estas localidades, com duração da viagem variando de seis até dez horas; a estrutura econ ${ }^{14}$ ômica de Imperatriz, que disponibiliza serviços similares em relação à capital tocantinense, além da menor distância para estes municípios - menos de duas horas (BESSA; CORADO, 2011; BRITO, 2009; OLIVEIRA, 2012).

Marabá/PA, localizado a 200 quilômetros de Imperatriz, também possui o tempo de deslocamento para os municípios do extremo norte tocantinense menor do que o de Palmas: até três horas de viagem rodoviária. Notam-se fortes ligações deste município paraense com o Nordeste, e estreita ligação com Araguaína, Goiânia, Palmas e São Paulo. Esta preferência por pessoas oriundas de outras partes do país deve-se a sua estrutura produtiva baseada na extração do minério de ferro, exigindo profissionais capacitados - engenheiros, geólogos e técnicos, que não são encontrados com facilidade na região. Além destes trabalhadores, Marabá recebe grupo de homens que procuram emprego no polo mineral de Carajás e, assim como Imperatriz/MA, recebe e distribui trabalhadores, principalmente nordestinos (BRITO, 2009; OLIVEIRA, 2012).

13 São municípios com pequena população - abaixo de vinte mil habitantes - e sem atividades econômicas de expressão, e os seus moradores possuem fraco poder de consumo. A função desta localidade é tipicamente de cidade-dormitório.

14 Imperatriz/MA localiza-se na divisa estadual, por isso o tempo de viagem é bem menor. 
Além disso, Imperatriz e Marabá atraem a população regional por meio de serviços hospitalares especializados, centros de ensino superior e aeroportos, que realizam conexão direta para o Centro-Sul do país. Em suma, a participação de Palmas neste espaço é fraca por causa da grande distância rodoviária, da ausência de voos regulares paras estas localidades e também pela inexistência de uma grande unidade mineradora, o que poderia facilitar a inserção do entorno da capital na dinâmica produtiva mineral, que é a base produtiva do Bico do Papagaio.

Palmas é um município que se direciona para o Centro Sul do país, e não para a região na qual está inserida. Esta afirmação parte da constatação de que os voos partindo da capital tocantinense têm como destino as cidades de Brasília, Goiânia e São Paulo, e nenhum tem como destino os aeroportos nordestinos ou do Pará ${ }^{15}$. Além disso, a maior parte dos habitantes de Palmas que utiliza a rodoviária tem como destino a capital de Goiás e do Brasil ou as cidades vizinhas: Porto Nacional, Paraíso e Miracema (BESSA e CORADO, 2011; BRITO, 2009).

A atração limitada que Palmas possui também é notada na parte sul do estado, onde os municípios localizados nesta região são atraídos pelo eixo Goiânia-Brasília. No sudoeste tocantinense, Palmas não possui tanta importância comercial $^{16}$, exceto no próprio município de Dianópolis ${ }^{17}$. No sudoeste, Gurupi polariza os municípios localizados nesta área, estando diretamente influenciado pela capital de Goiás. Estas capitais localizadas no Brasil Central exercem ampla polarização no Tocantins.

Portanto, além de estar dentro de uma área polarizada - Brasília/Goiânia -, Palmas não está integrado com os municípios-polo sub-regionais - Marabá/ PA e Imperatriz/MA, pois não manifestam intenso convívio cotidiano, como circulação, transbordo, comércio, trabalho, consumo e lazer. A longa dist ${ }^{18}$ ância rodoviária e as diferenças de produção colaboram para a formação desta fraca interação entre os maiores núcleos urbano da região.

O quadro exposto abaixo sintetiza as diferenças e semelhanças conclusivas entre os trabalhos utilizados para retratar a relação de Palmas com os demais núcleos urbanos.

15 Dados de 2006. Atualmente a companhia aérea Sete oferece voos diários para Marabá/ $\mathrm{PA}$, Altamira/PA, Belém/PA, Eldorado do Carajás/PA, Ourilândia/PA, e sem escalas para Redenção/PA. Imperatriz/MA continua fora dos serviços aéreos disponibilizados por Palmas.

16 Brito (2009) presencia a influência de Campos Lindos/GO como o principal centro comercial desta microrregião. Oliveira (2012) nota que Luís Eduardo Magalhães exerce efeito polarizador nos municípios localizados nas intermediações de Dianópolis.

17 Oliveira (2012) detectou-se interações espaciais entre Dianópolis e Palmas.

18 Empiricamente observa-se a grande presença de pessoas oriundas de Imperatriz na capital. Entretanto, o convívio social entre as duas cidades não é de perceptível. 
Quadro 1 - Diferenças de resultados e semelhanças entre os trabalhos de Brito (2009), Oliveira (2012), Bessa e Corado (2011).

\begin{tabular}{|c|c|c|c|}
\hline Parâmetro & Brito (2009) & Oliveira (2012) & $\begin{array}{c}\text { Bessa e Corado } \\
(2011)\end{array}$ \\
\hline $\begin{array}{l}\text { A função de } \\
\text { Palmas }\end{array}$ & $\begin{array}{l}\text { Principal ponto } \\
\text { nodal na rede urbana } \\
\text { regional }\end{array}$ & $\begin{array}{l}\text { Ponto polarizador, } \\
\text { porém atua de forma } \\
\text { restrita }\end{array}$ & $\begin{array}{c}\text { Agente que } \\
\text { hierarquiza a } \\
\text { estrutura urbana } \\
\text { estadual }\end{array}$ \\
\hline $\begin{array}{l}\text { Por que Palmas } \\
\text { possui esta } \\
\text { característica? }\end{array}$ & $\begin{array}{l}\text { Atraiu trabalhadores } \\
\text { de outras regiões, } \\
\text { além da boa } \\
\text { infraestrutura de } \\
\text { transportes }\end{array}$ & $\begin{array}{l}\text { Os outros municípios } \\
\text { não possuem uma } \\
\text { diversificação } \\
\text { produtiva igual à da } \\
\text { capital }\end{array}$ & $\begin{array}{l}\text { Acumulou funções } \\
\text { urbanas que outras } \\
\text { cidades do estado } \\
\text { não obtiveram }\end{array}$ \\
\hline $\begin{array}{l}\text { Para que Palmas } \\
\text { continua sendo } \\
\text { um centro } \\
\text { de referência } \\
\text { regional...? }\end{array}$ & $\begin{array}{l}\text { Esta função } \\
\text { encontra-se } \\
\text { consolidada. }\end{array}$ & $\begin{array}{c}\text { As outras localidades } \\
\text { do TO devem } \\
\text { desenvolver } \\
\text { atividades } \\
\text { condizentes com a } \\
\text { inâmica regional }\end{array}$ & $\begin{array}{c}\text { Deve-se } \\
\text { compreender o } \\
\text { papel de outros } \\
\text { agentes estruturantes } \\
\text { do território } \\
\text { tocantinense }\end{array}$ \\
\hline
\end{tabular}

Elaboração própria.

Nota-se que as pesquisas de Oliveira (2012) e Bessa e Corado (2011) sugerem aprofundar na compreensão da rede urbana do estado do Tocantins, analisando a função dos demais núcleos urbanos e propondo formas de inserir estes centros na dinâmica econômica estadual. Diante disso, prossegue-se a investigação sobre a função de Palmas no contexto do território Centro-Norte.

\section{METODOLOGIA}

A teoria de lugares centrais de Christaller afirma que as cidades têm como principal objetivo fornecer bens e serviços, como comércio atacadista e varejista, financeiros, administrativos, educacionais, hospitalares, culturais, lazer e diversão (RICHARDSON, 1981).

Para analisar o potencial de cada núcleo urbano em ofertar bens e serviços, utiliza-se o índice de concentração de Hirschman-Herfindahl (IHH). Este indicador mede a concentração de determinado setor na região $j$ comparando a uma região maior. Observe: 
Em que,

$\mathrm{PO}_{\mathrm{ij}}=$ participação do setor $i$ da região $j$;

$\mathrm{PO}_{\text {it }}=$ total do setor $i$ da região de referência;

$\mathrm{PO}_{\mathrm{tj}}=$ participação do total da região $j$;

$\mathrm{PO}_{\mathrm{tt}}=$ total da região de referência.

Se o IHH apresenta um valor positivo, indica que o setor $i$ da região $j$ está concentrado, exercendo um poder de atração maior, dada a sua especialização. Ao contrário, valores negativos indicam um baixo poder de atração em comparação com a região de referência (ALVES, 2012).

Os dados utilizados para o cálculo deste indicador provêm do Instituto Brasileiro de Geografia e Estatística - IBGE - refere-se ao Produto Interno Bruto Municipal - PIB e ao Valor adicionado bruto a preços correntes dos serviços, inclusive administração, saúde e educação públicas, e seguridade social por município. Estes dois parâmetros relacionam-se ao ano de 2000 e 2010.

A região de referência é o estado do Tocantins, somado com as microrregiões de Conceição do Araguaia/PA, Redenção/PA, Parauapebas/ PA e Marabá/PA, Gerais de Balsas/MA, Porto Franco/MA, Imperatriz/MA e Chapada das Mangabeira/MA, conforme mostra a Figura 2.

Figura 2 - A região de referência: estado do Tocantins e microrregiões selecionadas do estado do Pará e Maranhão - 2012.

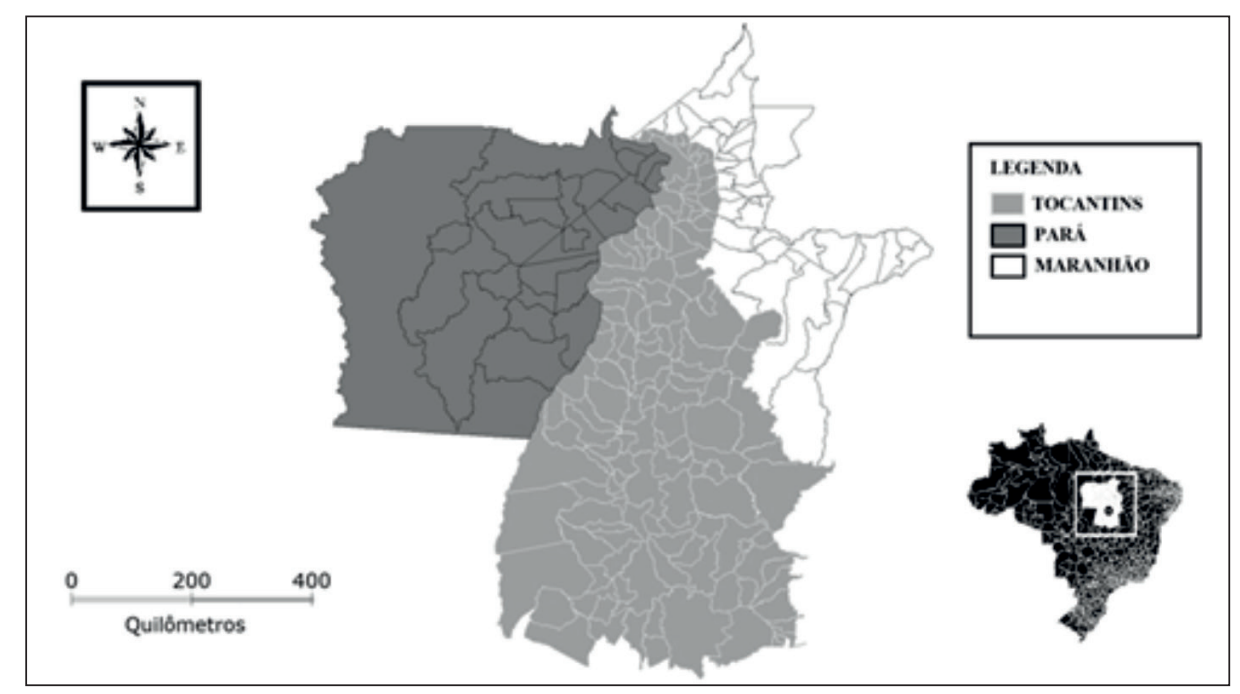

Fonte: Elaboração própria.

Este recorte geográfico é formado por duzentos municípios, sendo que cento e trinta e nove estão localizados no estado do Tocantins, vinte e quatro no 
estado do Pará, e trinta e cinco no estado do Maranhão. Além de Palmas/TO, estão inseridos nesta região os polos sub-regionais de Marabá/PA e Imperatriz/MA. O programa livre Terraview é utilizado para a elaboração dos mapas, facilitando a visualização dos resultados do IHH no ano de 2000 e 2010.

\section{RESULTADOS E DISCUSSÕES}

Nota-se que no ano de 2000 o conjunto de municípios formados por Palmas, Porto Nacional e Paraíso não possuem grande representatividade no setor de comércio e serviços. No período seguinte da análise, constata-se crescimento de $1.2 \%$, abaixo das microrregiões do Pará, que obtiveram o maior percentual no ano de 2010, retirando a primeira colocação dos demais municípios tocantinenses, que em 2000 detinha a maior participação neste setor. Esta constatação deve-se aos núcleos urbanos de Araguaína e Gurupi, pontos de referência nas partes norte e sul do Tocantins, respectivamente.

Tabela 1 - Percentual de participação no setor de serviços no estado de referência e a taxa de crescimento no período de 2000/2010, no Tocantins e nas microrregiões selecionadas do Pará e Maranhão.

\begin{tabular}{l|c|c|c}
\hline \multicolumn{1}{c|}{ Região } & 2000 & 2010 & $\begin{array}{c}\text { Taxa de crescimento } \\
2000 / 2010\end{array}$ \\
\hline Palmas, Porto Nacional e Paraíso & 14.0 & 15.7 & 1.2 \\
\hline Demais municípios do Tocantins & 32.4 & 30.2 & -0.7 \\
\hline Microrregiões selecionadas do Pará & 25.8 & 32.4 & 2.3 \\
\hline Microrregiões selecionadas do Maranhão & 27.9 & 21.7 & -2.5 \\
\hline
\end{tabular}

Fonte: IBGE. Elaboração própria.

As microrregiões do Maranhão perderam participação durante o período analisado (-2.5\%). Conforme observado no tópico anterior, Imperatriz atrai habitantes tanto no Maranhão, como no sul do Pará e norte do Tocantins. Portanto, devido a esta perda, as atividades urbanas nesta parte do estado do Maranhão podem estar concentradas em Imperatriz, sendo que os demais núcleos maranhenses perderam representatividade neste setor.

Enfatiza-se esta análise observando a participação deste setor em relação ao seu PIB. O objetivo desta investigação é detectar o nível de especialização de cada região analisada. A próxima tabela expõe este parâmetro, além de demonstrar a evolução destas atividades no período de 2000 a 2010. 
Tabela 2 - Percentual de participação no setor de serviços em relação ao PIB na região de referência e a taxa de crescimento no período de 2000/2010, no estado do Tocantins e nas microrregiões selecionadas do Pará e Maranhão.

\begin{tabular}{l|c|c|c}
\hline \multicolumn{1}{c|}{ Região } & 2000 & 2010 & $\begin{array}{c}\text { Tx de crescimento } \\
2000 / 2010\end{array}$ \\
\hline Palmas, Porto Nacional e Paraíso & 0.73 & 0.59 & -2.1 \\
\hline Demais municípios do Tocantins & 0.62 & 0.54 & -1.4 \\
\hline Microrregiões selecionadas do Pará & 0.36 & 0.24 & -4.0 \\
\hline $\begin{array}{l}\text { Microrregiões selecionadas do } \\
\text { Maranhão }\end{array}$ & 0.59 & 0.53 & -1.1 \\
\hline
\end{tabular}

Fonte: IBGE. Elaboração própria.

Em geral, todas as regiões obtiveram taxa de crescimento negativo, indicando que o setor de serviços está perdendo participação em relação aos demais setores. As microrregiões selecionadas do Pará apresentaram maior perda neste ínterim (-4.0\%), demonstrando que as economias destes municípios podem estar em fase de diversificação ou expansão de certas atividades primárias, como a mineração, extrativismo e agropecuária, que são bastante representativas no sudeste do Pará.

Por outro lado, os demais municípios do Tocantins e as microrregiões selecionadas do Maranhão foram os que apresentaram as menores perdas de participação do setor analisado em relação ao PIB. Este resultado aponta que não ocorre uma forte diversificação produtiva, como a que vem acontecendo nas microrregiões do sul paraense.

Os municípios de Palmas, Porto Nacional e Paraíso, apesar da forte queda (-2.1\%) no período de 2000 a 2010, permanecem como a região especializada no setor de serviços. No ano de 2010, quase 60\% do Produto Interno Bruto é composto por atividades urbanas, apontando a importância desta produção na economia destes núcleos, apesar da perda observada.

Esses resultados, apesar de sua relevância, não indicam os municípios que concentram as atividades relacionadas ao setor de serviços. Utilizando o Índice de Herfindahl-Hirschman, pode-se visualizar, por meio de mapas coropléticos, como está distribuído espacialmente este indicador na região de estudo.

Os municípios que concentram o setor de serviços no recorte geográfico analisado são Palmas/TO, Araguaína/TO, Imperatriz/MA, Balsas/MA e Marabá/PA. Com dez anos de existência, a capital tocantinense acumulava funções tipicamente urbanas, e, em menor nível, Porto Nacional e Paraíso complementam a estrutura produtiva terciária do estado do Tocantins. Nos 
demais municípios tocantinenses, Araguaína centraliza a produção terciária no norte, e ao longo da rodovia BR - 153, a Belém-Brasília, Colinas/TO, Guaraí/ TO e Gurupi apresentam significativa aglutinação produtiva. Nota-se que os municípios tocantinenses citados possuem as maiores populações urbanas do estado, demonstrando que pode existir uma relação entre concentração populacional e produção terciária representativa.

Mapa 1 - IHH do Valor adicionado bruto a preços correntes dos serviços, inclusive adm., saúde e educação públicas, e seguridade social, Tocantins, Pará e Maranhão - 2000.

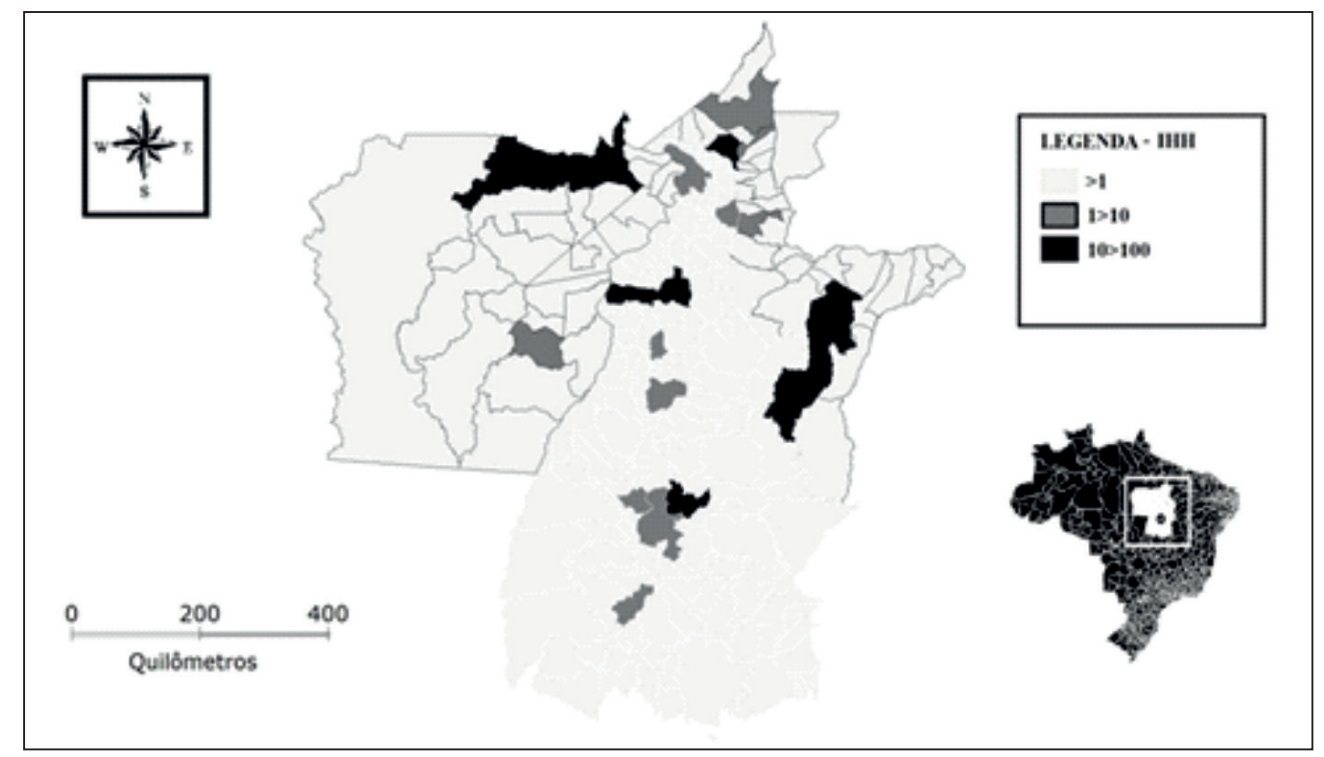

Fonte: IBGE. Elaboração própria.

Nas microrregiões vizinhas, Imperatriz e Marabá confirmam-se como os principais núcleos atrativos da região. Porém, diferentemente do que se nota no Maranhão, onde existem dois polos de serviços: Balsas e Imperatriz, e outros de menor expressão - Porto Franco, Açailândia e João Lisboa -, o estado do Pará concentra esta produção em Marabá, apesar de Redenção, no extremo sul do estado, destacar-se nos serviços urbanos.

Por fim, esse mapa demonstra a hierarquia da rede urbana na região delimitada no ano de 2000. Os serviços no estado do Tocantins estão concentrados em Palmas, Porto Nacional e cidades localizadas ao longo da Belém-Brasília. As grandes cidades do sul maranhense e paraense também participam desta dinâmica, destacando-se Imperatriz e Balsas, porém restringindo-se apenas a essas. O próximo mapa expõe se em dez anos esta estrutura produtiva passou por transformações. 
Mapa 2 - IHH do Valor adicionado bruto a preços correntes dos serviços, inclusive adm., saúde e educação públicas, e seguridade social, no Tocantins, Pará e Maranhão - 2010.

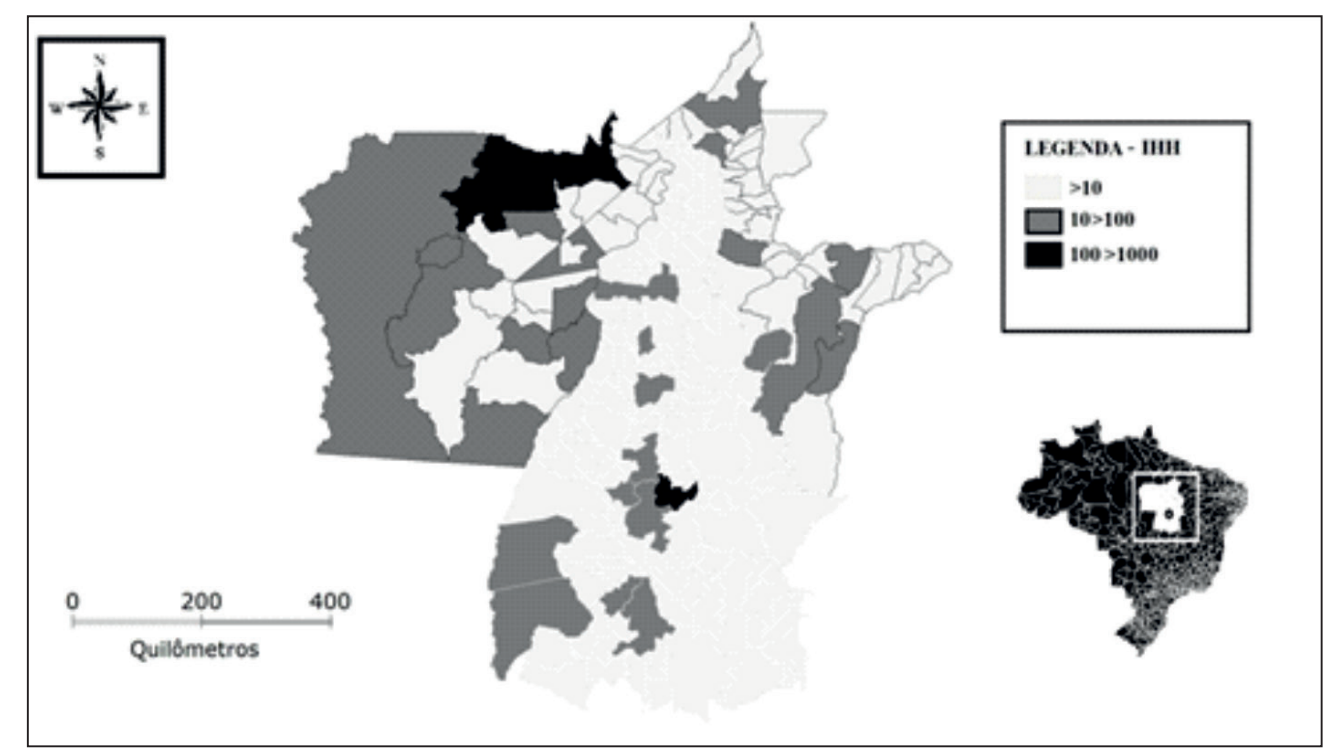

Fonte: IBGE. Elaboração própria.

Analisando o Mapa 4, observam-se mudanças na distribuição espacial do IHH serviços em relação ao ano de 2000. O estado do Pará, que antes concentrava esta produção em Marabá, e com menor nível em Redenção, no ano de 2010 encontra-se dispersa, destacando como ponto concentrador o município de Parauapebas.

Ademais, Santana do Araguaia, São Félix do Xingu, Conceição do Araguaia, Floresta do Araguaia, Xinguara, Ourilândia do Norte, Tucumã e Canaã do Carajás, também aglutinam serviços que dez anos atrás o IHH não constatava. Portanto, as microrregiões sul paraense estão passando por um processo de diversificação produtiva, diferentemente do que ocorre no Maranhão: Imperatriz não acompanhou o desempenho dos demais polos sub-regionais. A única transformação observada neste estado é a inclusão de municípios ao redor de Balsas, como Tasso Fragoso e São Raimundo das Mangabeiras, e a substituição de Porto Franco por Estreito. Este município no final da primeira década do século XXI recebeu grandes contingentes de pessoas para trabalhar nas obras da Ferrovia Norte-Sul e na Usina Hidroelétrica de Estreito, atraindo unidades terciárias para o seu núcleo urbano.

Em relação ao estado do Tocantins, Palmas permanece como o principal centro de serviços, e Araguaína não conseguiu acompanhar a evolução da capital. 
Todavia, percebe-se a incorporação de municípios tocantinenses que conseguem concentrar estas atividades, como Campos Lindos, no nordeste; Miracema, no centro; Formoso do Araguaia, Lagoa da Confusão e Peixe; no sudoeste.

Oliveira (2012) aponta que Campos Lindos e Formoso do Araguaia são os principais polos agropecuários do Tocantins. Os resultados do IHH mostram que estes núcleos, além de possuírem uma grande produção agropecuária, conseguem acumular funções urbanas. Trata-se de uma evolução produtiva que estas localidades situadas no nordeste e sudoeste tocantinense, respectivamente, estão presenciando. Por outro lado, ao redor de Araguaína, o indicador não detecta municípios que concentram serviços; do mesmo modo ocorre na microrregião de Dianópolis, no sudeste, em ambos os períodos analisados.

Prosseguindo com a análise, observa-se que Marabá é o principal ponto de referência no restante do Pará, tendo a companhia de Parauapebas. Este é um importante polo minerador nacional, produzindo minério de ferro e exportando-o para o exterior. Em menor nível, surgem municípios que acompanham a tendência destes dois núcleos, demonstrando que esta sub-região concentra a maior parte dos serviços. Este grupo de municípios foi o que mais perdeu participação do setor de serviços no PIB. Esta perda pode estar relacionada à expansão dos ganhos do setor primário, retirando a participação do terciário.

Devido à crescente expansão das atividades urbanas nas microrregiões do sudeste paraense, Palmas tende a comandar municípios localizados ao sul do Tocantins, podendo diminuir a polarização exercida por Goiânia e Brasília. Entretanto, nota-se que o restante do estado não possui a característica de diversificar a produção com serviços coletivos. Além disso, os municípios maranhenses perderam participação neste setor, o que pode diminuir o poder que a região possui em "interiorizar" os ganhos produtivos.

Diante dessas constatações, nota-se que o direcionamento de Palmas para o eixo Brasília-Goiânia-São Paulo contribui para que a capital tocantinense reordene os núcleos urbanos do Sudoeste para o Centro-Sul, servindo como ponto de ligação entre esta região e o restante do país. O mapa a seguir ilustra esta hierarquização.

Com o adensamento produtivo no sudeste paraense, Marabá tende a comandar a região do Bico do Papagaio, rivalizando com Palmas no que tange a exercer atração nas cidades do norte tocantinense. Devido a esta competição, a capital tocantinense direciona-se para a parte sul do estado, precisamente para as microrregiões do Rio Formoso e Gurupi, onde não sofre a concorrência de nenhum núcleo sub-regional. 
Mapa 3 - Estrutura urbana no Centro-Norte - 2010.

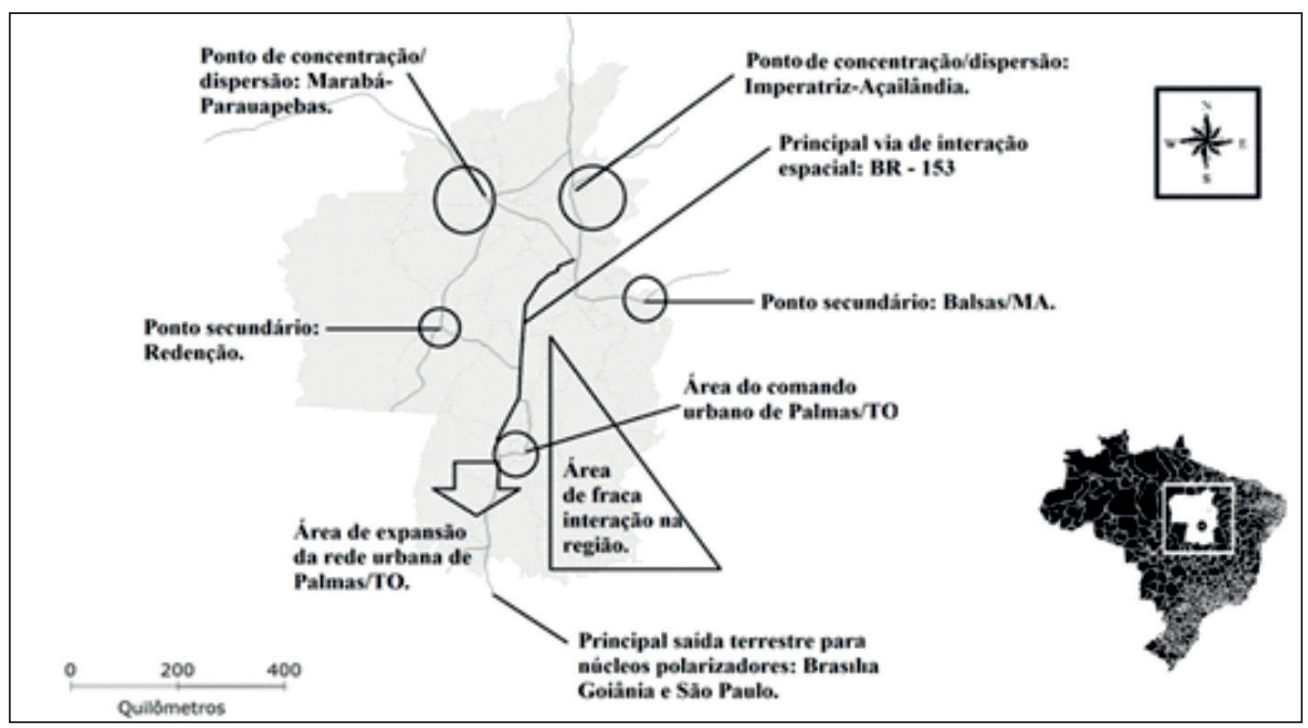

Fonte: IBGE. Elaboração própria.

Nota-se no mapa a existência de uma área com fraca interação regional, formada por municípios da microrregião do Jalapão e Dianópolis e que estão diretamente ligadas ao comando de Brasília, e também, a cidade de Barreiras e Luís Eduardo Magalhães, no oeste da Bahia, região de grande produtividade agrícola e oferta de serviços urbanos.

\section{CONCLUSÃO}

Para que Palmas se torne um lugar central, necessita diversificar os serviços coletivos, além de aumentar os fluxos de capital com os dois polos subregionais - Marabá/PA e Imperatriz/MA. A partir deste ponto, pode-se pensar em uma rede hierárquica no Centro-Norte do país. Atualmente, observa-se que a capital tocantinense estabeleceu uma relação de dependência com Paraíso e Porto Nacional, tendendo a fixar esta conformidade com os núcleos localizados no sudoeste do estado. Portanto, Palmas não é um enclave, porém o seu poder de comando no território é bastante restrito.

Os trabalhos empíricos, apesar das diferenças metodológicas, citam que a capital do Tocantins possui potencialidades, como renda média e nível de produção elevado, atraindo a população de outras partes. Contudo, o comando no território restringe-se apenas aos municípios localizados em seu redor: Porto Nacional, Paraíso e Miracema do Tocantins. Ademais, o indicador HerfindahlHirschman aponta a concentração da produção de serviços nas microrregiões do 
sudeste do Pará, diferentemente do que ocorre no Tocantins, onde há grandes agrupamentos municipais que não possuem esta característica.

Essa limitação deve-se à fraca diversificação produtiva no espaço geográfico analisado. Os complexos industriais e as atividades primárias que podem induzir o surgimento de atividades produtivas urbanas concentram-se em Palmas, Marabá, Parauapebas e Imperatriz. Devido a este cenário, a capital tocantinense pouco interage com os núcleos localizados no Bico do Papagaio, devido à forte atração exercida por Marabá-Parauapebas, e em menor nível por Imperatriz. Portanto, existem dois sistemas urbanos no Centro-Norte: o de Palmas, no comando da parte central e sudoeste do Tocantins, e o de ImperatrizMarabá, no norte tocantinense e microrregiões estaduais limítrofes. Especula-se a existência de um terceiro comando, no sudeste do estado do Tocantins, onde Brasília e possivelmente Barreiras/BA e Luís Eduardo Magalhães/BA exercem maior atração do que Palmas.

No arcabouço desses resultados, Palmas não está inserido no contexto de lugar central proposto por Brasil (2008). A capital tocantinense possui vantagens citadas anteriormente, todavia, para exercer o comando macrorregional, necessita que os demais municípios comecem a diversificar a sua produção, podendo iniciar pela produção primária, do mesmo modo que ocorreu no sudeste paraense e sudoeste tocantinense.

Para os próximos trabalhos, recomenda-se aprofundar a investigação nos polos sub-regionais - Marabá/PA, Imperatriz/MA, Barreiras/BA-Luís Eduardo Magalhães/BA e Araguaína/TO, para observar quais são as suas relações espaciais, e como Palmas pode inserir-se neste contexto, podendo aumentar o seu poder de comando regional.

Por fim, as populações dos municípios interioranos devem possuir acesso à renda, possibilitando o consumo nos polos do Centro-Norte. Portanto, é necessário aprofundar o conhecimento sobre mercado de trabalho nestas localidades, pois sem esta condição a capital do Tocantins encontrará dificuldades em tornar-se um lugar central.

\section{REFERÊNCIAS}

ALVES, Lucir Reinaldo. Indicadores de localização, especialização e estruturação regional. PIACENTI, Carlos Alberto; LIMA, Jandir Ferrera (org.). In: Análise regional: metodologias e indicadores. Curitiba/PR: Camões, 2012.

AMARAL FILHO, Jair. A endogeneização no desenvolvimento econômico regional e local. IPEA - Planejamento e Políticas Públicas. Brasília/DF: n.23, jun 2001. 
BECKER, Bertha K. Dinâmica urbana na Amazônia. In: DINIZ, Clélio Campolina; LEMOS Mauro Borges (Orgs.). Economia e Território. Belo Horizonte: UFMG, 2005.

BESSA, K.; CORADO, V. A dinâmica recente do segmento da rede urbana no Tocantins: as implicações da construção de Palmas para Porto Nacional. GeoRedes, Salvador/BA, vol.7, n.11, jul. 2011.

BRASIL. Estudo da dimensão territorial para o planejamento: Volume III - Regiões de Referência. Brasília: MP, 2008.

BRITO, Eliseu Pereira de. O papel de Palmas - TO na rede de integração regional. Dissertação (Mestrado em Geografia). Dourados/MS: UFGD, 2009.

DINIZ, Clélio Campolina; GONÇALVES, Eduardo. Economia do conhecimento e desenvolvimento regional no Brasil. In: DINIZ, Clélio Campolina; LEMOS Mauro Borges (Orgs.). Economia e território. Belo Horizonte: UFMG, 2005.

HILHORST, Joe G.M. Planejamento regional: enfoque sobre sistemas. Rio de Janeiro: Zahar, 1981.

LIRA, Elizeu Ribeiro de. A gênese de Palmas - Tocantins: a geopolítica de re(ocupação) territorial na Amazônia Legal. Goiânia: Kelps, 2011.

OLIVEIRA, Thiago José Arruda. Interações produtivas no Estado do Tocantins: uma análise espacial. Dissertação (Mestrado em Desenvolvimento Regional). Palmas/TO: UFT, 2012.

RICHARDSON, Harry W. Economia regional: teoria da localização, estrutura urbana e crescimento regional. Rio de Janeiro: Zahar, 1981.

RODRIGUES, Jean Carlos. Estado do Tocantins: política e religião na construção do espaço tocantinense. São Paulo: Blucher, 2010.

SANTOS, Milton. Economia espacial: críticas e alternativas. São Paulo: Editora da USP, 2003.

STORPER, Michael; VENABLES, Anthony J. O burburinho: a força econômica da cidade. In: DINIZ, Clélio Campolina; LEMOS Mauro Borges (Orgs.). Economia e Território. Belo Horizonte: UFMG, 2005.

Texto submetido à Revista em 23.01.2015

Aceito para publicação em 15.06.2015 